\title{
Hyperpigmentation of the hard palate mucosa in a patient with chronic myeloid leukaemia taking imatinib
}

\author{
Gian Paolo Bombeccari ${ }^{1,2}$, Umberto Garagiola ${ }^{1,2^{*}}$, Francesco Pallotti ${ }^{2,3}$, Margherita Rossi ${ }^{1}$, Massimo Porrini ${ }^{1}$,
} Aldo Bruno Giannì ${ }^{1,2}$ and Francesco Spadari, ${ }^{1,2}$

\begin{abstract}
Background: Imatinib mesylate is an inhibitor of the tyrosine kinase Bcr-Abl and a first-line treatment for Philadelphia chromosome-positive chronic myeloid leukaemia (CML). Dermatological side effects include superficial oedema, pustular eruption, lichenoid reactions, erythroderma, and skin rash. Depigmentation of the skin and/or mucosa is uncommon, and hyperpigmentation is rare.

Case presentation: We present the case of a 63-year-old Caucasian male with widespread hyperpigmentation of the hard palate associated with a 9-year history of imatinib therapy to treat CML. He did not complain of any symptoms. Clinical examination did not reveal any abnormal pigmentation of the skin or other region of the oral mucosa. He did not smoke cigarettes or drink alcohol. His medication regimen was a proton pump inhibitor, a beta-blocker, cardioaspirin, atorvastatin, and imatinib $400 \mathrm{mg} /$ day. Histopathologically, melanin and haemosiderin deposits were evident in the lamina propria. The lesion persisted, with no clinical change, through several follow-ups. We reviewed the literature to explore the possible relationship between oral hyperpigmentation and long-term imatinib mesylate treatment.

Conclusions: We diagnosed oral pigmentation associated with imatinib intake based on the medical history and clinical features of the pigmented macules. Oral pigmentation may have a variety of causes, and differential diagnosis requires nodal analysis. Clinicians should be aware of possible oral mucosal hyperpigmentation in patients taking imatinib mesylate. Such pigmentation is benign and no treatment is needed, but surveillance is advisable.
\end{abstract}

Keywords: Chronic myeloid leukaemia, Oral melanosis, Drug-induced oral reactions, Oral pigmentation, Mucosal pigmentation

\section{Background}

Pigmentation of the oral mucosa associated with overproduction of melanin is relatively common and may involve any region of the oral cavity. The prevalence varies by geographical region and ethnicity. A cross-sectional study of 1275 Jordanian subjects found that $30.2 \%$ exhibited oral pigmentation [1]. In Sweden, such lesions are found in about $10 \%$ of the population [2]. The differential

\footnotetext{
* Correspondence: umberto.garagiola@unimi.it

'Maxillo-Facial and Dental Unit, Fondazione Ca' Granda IRCCS Ospedale Maggiore Policlinico, University of Milan, Via Commenda 10, 20122 Milan, Italy

${ }^{2}$ Department of Biomedical, Surgical and Dental Sciences, University of Milan, Milan, Italy

Full list of author information is available at the end of the article
}

diagnosis includes physiological and environmental causes, as well as manifestations of systemic disease [3]. Drug-induced pigmentation constitutes $10-20 \%$ of all cases of acquired hyperpigmentation and should be considered during diagnosis, especially in elderly patients on multidrug therapy [4]. The aetiology of drug-induced pigmentation varies with the causative drug. One or more of three potential pathways may be involved: these are deposition of the drug per se or a metabolite thereof, stimulation of melanin production, and bacterial metabolism of the drug, alone or in combination [5]. The colour ranges from brown (associated with the use of oral contraceptives) to blue-black (often associated with hydroxychloroquine treatment) $[5,6]$. 
Imatinib mesylate (Gleevec ${ }^{\circ}$; Novartis, Basel, Switzerland), a tyrosine kinase inhibitor targeting the Bcr-Abl protein, is a first-line treatment for Philadelphia chromosome-positive CML [7]. The dermatological side effects include superficial oedema and skin rash (the most frequent side effects), pustular and/or lichenoid eruptions, erythroderma, graftversus-host-like disease, and small-vessel vasculitis [8-10]. Hypopigmentation of the skin and/or mucosa is an uncommon side effect [11]. Intraoral side effects are unusual and, in a few cases, have included lichenoid reactions [12-14] and dental pigmentation [15-17]. Rarely, hyperpigmentation of the hard palate has been observed, presumably related to drug intake [3, 18-23]. Here, we describe a case of widespread hyperpigmentation of the hard palate mucosa associated with long-term imatinib treatment of a CML patient.

\section{Case presentation}

In January 2016, a 63-year-old Caucasian male was referred to us for evaluation of painless grey-blue hyperpigmentation of the hard palate, noted by his dentist during a routine dental examination (Fig. 1). His medical history included hypertension, hyperlipidaemia, and CML diagnosed about 10 years prior. His medication regimen was a proton pump inhibitor $(20 \mathrm{mg} /$ day $)$, a beta-blocker $(50 \mathrm{mg} /$ day $)$, cardioaspirin $(100 \mathrm{mg} /$ day $)$, atorvastatin $(20 \mathrm{mg} /$ day $)$, and imatinib $(400 \mathrm{mg} /$ day $)$. He had been taking imatinib for about 9 years. He had never taken hydroxyurea, minocycline, or any anti-malarial agent. Clinical examination revealed no abnormal pigmentation of the skin or other region of the oral mucosa. He denied smoking and alcohol consumption. We scheduled a complete blood count test and screening for Addison's disease. No serological abnormalities were evident. Under local anaesthesia, we performed a 3-mm incisional punch biopsy. The histopathological report and medical history were consistent with druginduced palatal hyperpigmentation. We diagnosed mucosal

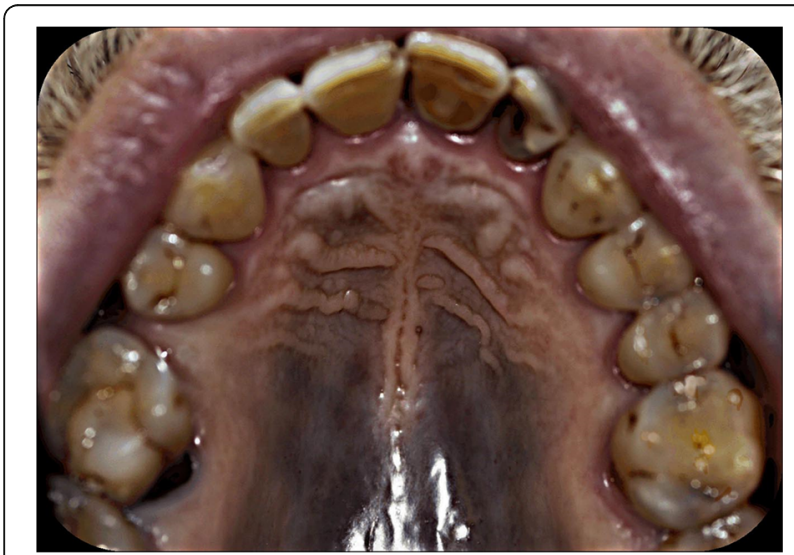

Fig. 1 An extensive blue-grey pigmented lesion of the hard palate mucosa evident on clinical examination pigmentation associated with imatinib therapy, thus excluding other environmental, physiological, and pathological causes (Table 1).

\section{Histopathological findings}

Histopathological examination revealed a non-inflamed palatal mucosa with pigment-containing histiocytes in the mucous membrane (Fig. 2). Immunohistochemically, both haemosiderin (Perl's Prussian blue staining) and melanin (Fontana-Masson staining) were detected (Figs. 3 and 4).

\section{Outcome and follow-ups}

At the 6-month follow-up, neck ultrasonography did not reveal any swollen lymph node. We took close-up colour photographs of the lesion to confirm the absence of any

Table 1 Conditions associated with mucosal pigmentation that should be considered during the differential diagnosis of oral melanosis [1, 6, 25-27]

Environmental causes

Smoking-associated melanosis

Heavy metal pigmentation due to metallic deposit

Dental amalgam tattoos

Drug-induced pigmentation

Physiological causes

Physiological ethnic and/or racial pigmentation

Labial melanotic macule

Oral melanocytic nevi

Pathological causes

Post-inflammatory deposits of melanin

Peutz-Jeghers syndrome

AIDS

Hemochromatosis

Addison's disease

Laugier-Hunziker disease

Oral melanoacanthoma

Pseudo-ochronosis

Bandler's syndrome

McCune-Albright syndrome

Cowden syndrome

Neurofibromatosis

Riehl's melanosis

LAMB syndrome (Carney complex)

Polyostotic fibrous dysplasia syndrome

LEOPARD syndrome

Hyperthyroidism

Nelson's syndrome

Melanosis associated with melanoma 


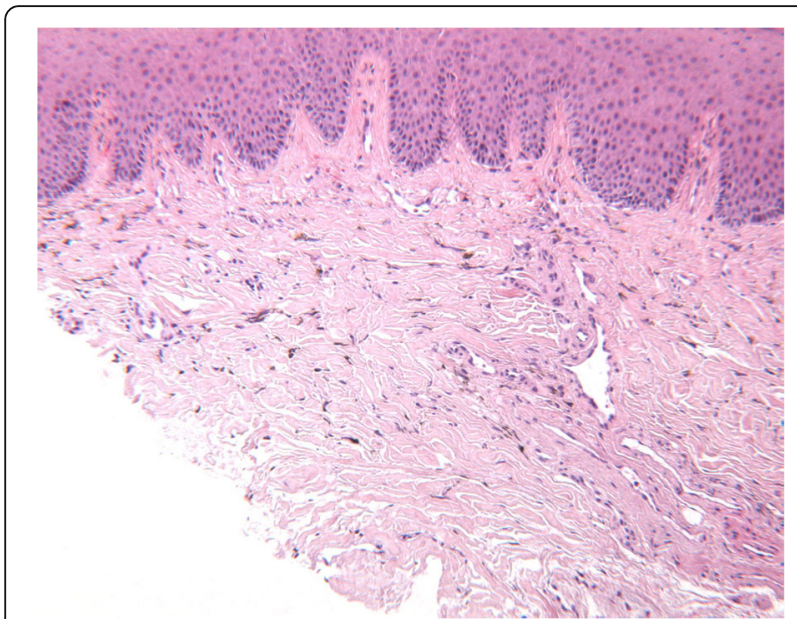

Fig. 2 The lamina propria of the oral mucosa contained brown pigment scattered between collagen fibres and in the cytoplasm of macrophages $(H \& E \times 10)$

morphological change. In May 2017, palatal hyperpigmentation was still evident, and the clinical appearance was unchanged, but he reported no symptoms.

\section{Discussion}

Diagnostic considerations when encountering oral melanosis should include physiological, pathological, and environmental variables. Physiological oral melanosis is usually localised to the gingival and buccal mucosa and is bilateral and symmetrical, brownish in colour, and clinically more common among dark-skinned populations [1]. Oral melanotic macules present as wellcircumscribed brown-to-black flat lesions, mainly on the lower vermilion. The pathogenesis of physiological melanotic macules remains controversial; both reactive and genetic factors may be involved [6]. Oral nevi typically

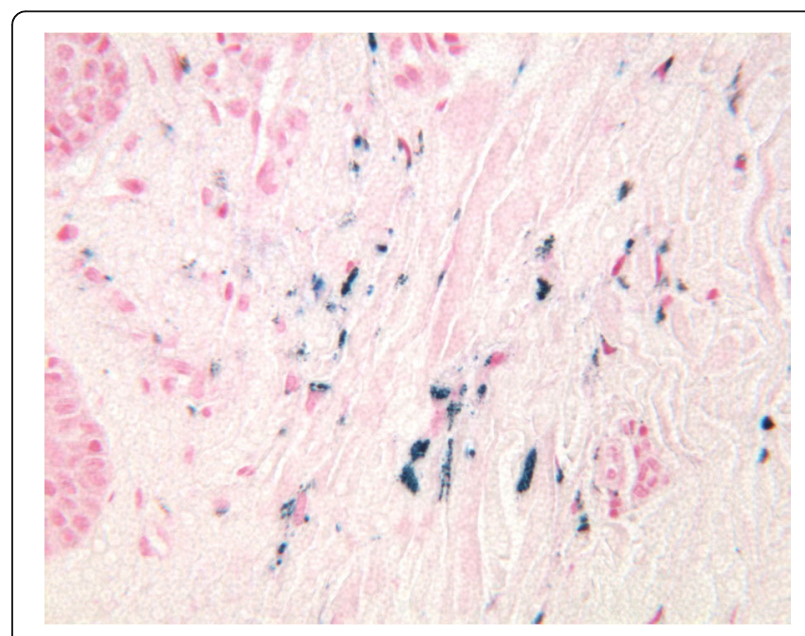

Fig. 3 The lamina propria of the oral mucosa contained blue-staining spherical particles that included iron (Perl's stain, $\times 40$ )

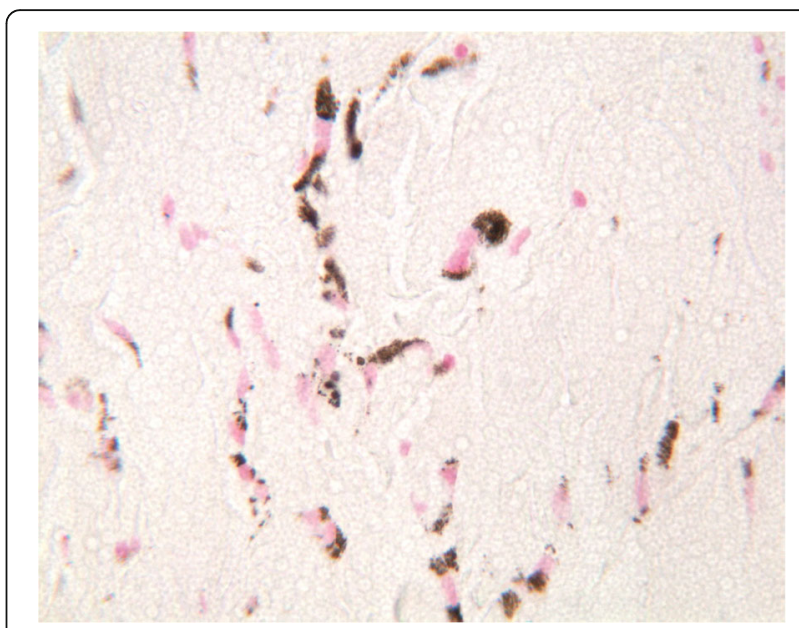

Fig. 4 The lamina propria of the oral mucosa contained brown-staining spherical particles that included melanin (Fontana-Masson staining, $\times 40$ )

appear as solitary brown-to-black mucosal macules, mainly on the palate and buccal mucosa. Although the pathogenesis of nevi remains unknown, it has been suggested that the lesions are benign neoplasms. No malignant transformation of oral nevi has yet been reported, and no evidence points to an increased risk of oral melanoma in affected subjects [24]. Notably, palatal melanosis must be differentiated from an oral melanoma, which may present as an asymptomatic brown-to-grey-black macula with irregular borders. Further, an oral melanoma grows rapidly and exhibits ulcerative evolution with bleeding and pain [25] Several systemic diseases, including Addison's disease, Peutz-Jeghers syndrome, McCune-Albright syndrome, Cowden syndrome, neurofibromatosis, acquired immunodeficiency syndrome, haemochromatosis, and hyperthyroidism, as well as uncommon conditions such as Nelson's syndrome, polyostotic fibrous dysplasia syndrome, Laugier-Hunziker syndrome, and the Carney complex, may feature oral melanotic macules [1, 26, 27]. Melanosis associated with these conditions is due to increased levels of melanin within the basal cell layer, attributable to incontinent melanophages in the lamina propria, in the absence of iron deposits and bleeding $[3,28]$. Oral pigmentation induced by smoking (smoker's melanosis) may be associated with the effects of components of tobacco on oral melanocytes [29]. It has been hypothesised that stimulation of melanin production may be a protective reaction of the oral mucosa, associated with detoxification of polycyclic amines and benzopyrenes, thus being a side effect of tobacco use [30]. Post-inflammatory melanin deposits scattered throughout the oral connective tissue are frequently observed in patients with chronic inflammatory diseases such as oral lichen planus, pemphigoid, and pemphigus [31]. Hyperpigmentation following inflammation may be caused by an increase in melanogenesis triggered by cytokines and 
reactive oxygen species, which induce melanocyte activity and the proliferation of dendritic cells, and increase tyrosinase activity [31, 32].

A history of occupational or environmental exposure to heavy metals and clinical signs of metal toxicity help to identify pigmentations of the oral mucosa. Heavy metals such as bismuth, lead, copper, arsenic, gold, copper, cobalt, chromium, silver, mercury, and magnesium can induce the development of a bluish-black line, the so-called Burton's line, along the gingival margin, the thickness of which is proportional to the extent of gingival inflammation [31]. In some cases, however, the hard palate mucosa adjacent to amalgam dental fillings develops blue-grey macules, termed the "amalgam tattoo." Histologically, the amalgam tattoo presents as discrete dark granules or fragments, usually surrounding collagen bundles and blood vessels, associated with low-level infiltrations of inflammatory cells [33]. The aetiology of medication-associated oral pigmentation may be related to the use of drugs that induce melanin formation. These include clofazimine used to treat leprosy, anti-malarials such as quinine, and immunomodulatory agents. In patients on hormonal therapy, conjugated oestrogens can lower the serum cortisol concentration by stimulating adrenocorticotropic hormone (ACTH) production. Notably, oral hyperpigmentation induced by anti-malarials, minocycline, and imatinib often involves the mucosa of the hard palate [18]. Histopathologically, imatinib-induced oral pigmentation usually presents as spherical pigmented melanin bundles in the lamina propria, with no sign of inflammation or haemorrhage [3, 18-20, 23].

Of the 15 cases published in the English language literature, eight reported the histopathological features, i.e. deposits of melanin and/or haemosiderin in the lamina propria. Of these, four described co-existing melanin and haemosiderin deposits. Our findings are consistent with those of the cited reports; both Fontana-Masson staining for melanin and Perl's Prussian blue staining for haemosiderin were positive (Table 2).

The pathophysiological mechanism of mucocutaneous pigmentation induced by imatinib remains unclear. Imatinib targets the ATP-binding site of the Bcr-Abl tyrosine kinase and also inhibits the actions of other tyrosine kinases, including platelet-derived growth factor receptor-b, C-kit, and C-ABL [17]. C-kit is a transmembrane growth factor expressed in basal skin cells, melanocytes, epithelial cells of the breast, and mast cells, stimulation of which leads to activation (followed by the

Table 2 Summary of previous case reports on oral mucosal pigmentation associated with imatinib therapy

\begin{tabular}{|c|c|c|c|c|c|c|}
\hline Author(s), year & $\begin{array}{l}\text { Duration of } \\
\text { treatment } \\
\text { with imatinib }\end{array}$ & $\begin{array}{l}\text { Dosage } \\
\text { (mg/dose) }\end{array}$ & $\begin{array}{l}\text { Age and sex } \\
\text { of patient }\end{array}$ & $\begin{array}{l}\text { Site(s) } \\
\text { affected }\end{array}$ & $\begin{array}{l}\text { Histological } \\
\text { findings }\end{array}$ & $\begin{array}{l}\text { Condition } \\
\text { treated }\end{array}$ \\
\hline $\begin{array}{l}\text { Singh and Bakhshi } \\
2007 \text { [15] }\end{array}$ & 4 years & 300 & $13 \mathrm{~F}$ & Gingivae, teeth & Clinical diagnosis only & CML \\
\hline Lewis, 2009 [18] & Unknown & 800 & $70 \mathrm{M}$ & Palate & $\begin{array}{l}\text { Melanin and haemosiderin deposits in } \\
\text { lamina propria }\end{array}$ & CML \\
\hline $\begin{array}{l}\text { Mcpherson et al. } \\
2009 \text { [38] }\end{array}$ & 6 years & Unknown & $59 \mathrm{~F}$ & $\begin{array}{l}\text { Gingivae, toes, } \\
\text { fingernails }\end{array}$ & Clinical diagnosis only & CML \\
\hline $\begin{array}{l}\text { Wong et al. } 2011 \\
\text { [19] }\end{array}$ & 3 months & Unknown & $43 \mathrm{~F}$ & Palate & Melanin deposits in lamina propria & CML \\
\hline $\begin{array}{l}\text { Mattsson et al. } 2011 \\
\text { [20] }\end{array}$ & $\begin{array}{l}5 \text { years } \\
5 \text { years } \\
5 \text { years }\end{array}$ & $\begin{array}{l}400 \\
400 \\
400\end{array}$ & $\begin{array}{l}66 \mathrm{~F} \\
66 \mathrm{~F} \\
64 \mathrm{~F}\end{array}$ & $\begin{array}{l}\text { Palate } \\
\text { Palate } \\
\text { Palate }\end{array}$ & $\begin{array}{l}\text { Melanin deposits in lamina propria } \\
\text { Clinical diagnosis only }\end{array}$ & $\begin{array}{l}\text { Metastatic gastrointestinal } \\
\text { stromal tumour } \\
\text { CML } \\
\text { CML }\end{array}$ \\
\hline Li et al. 2012 [3] & $\begin{array}{l}4 \text { years } \\
10 \text { years } \\
5 \text { years }\end{array}$ & $\begin{array}{l}400 \\
400 \\
400\end{array}$ & $\begin{array}{l}64 M \\
53 M \\
29 F\end{array}$ & $\begin{array}{l}\text { Palate } \\
\text { Palate } \\
\text { Palate }\end{array}$ & $\begin{array}{l}\text { Melanin and haemosiderin deposits } \\
\text { in lamina proria }\end{array}$ & $\begin{array}{l}\text { CML } \\
\text { CML } \\
\text { Pelvic fibromatosis }\end{array}$ \\
\hline $\begin{array}{l}\text { Resende et al. } 2012 \\
\text { [21] }\end{array}$ & 5 years & 600 & $38 \mathrm{M}$ & $\begin{array}{l}\text { Palate, nose, } \\
\text { earlobes }\end{array}$ & Clinical diagnosis only & $\begin{array}{l}\text { Post-haematopoietic stem } \\
\text { Cells transplant }\end{array}$ \\
\hline $\begin{array}{l}\text { Roeker and } \\
\text { Wolanskyj } 2014 \text { [22] }\end{array}$ & 6 years & Unknown & $65 \mathrm{~F}$ & Palate & Clinical diagnosis only & CML \\
\hline $\begin{array}{l}\text { Song and Kang } \\
2014 \text { [23] }\end{array}$ & Unknown & Unknown & $58 \mathrm{M}$ & Palate, nose & Clinical diagnosis only & CML \\
\hline $\begin{array}{l}\text { Lyne et al. } 2015 \\
\text { [24] }\end{array}$ & 13 years & $400-600$ & $58 \mathrm{~F}$ & Palate & $\begin{array}{l}\text { Haemosiderin deposits in lamina } \\
\text { propria }\end{array}$ & CML \\
\hline $\begin{array}{l}\text { Romeo et al. } 2015 \\
\text { [39] }\end{array}$ & 11 years & 400 & $72 \mathrm{~F}$ & Palate & $\begin{array}{l}\text { Brown spherical bodies located within } \\
\text { the lamina propria }\end{array}$ & CML \\
\hline
\end{tabular}


rapid degradation) of microphthalmia transcription factor (MITF); in turn, this transactivates the promoter of the tyrosinase pigmentation gene of melanocytes [9]. It has been suggested that imatinib inhibits ligand binding to specific receptors on the surfaces of human melanocytes, reducing cellular activity and thus commonly triggering hypopigmentation [10]. However, imatinib may rarely cause hyperpigmentation of the skin and/or mucosae; a metabolite of the drug may chelate iron and melanin, as do minocycline and anti-malarial drugs [3]. Currently, it is not known why the mucosa of the hard palate is the tissue invariably affected by hyperpigmentation. However, the palate contains a large number of mucosal melanocytes [34] in which imatinib metabolites accumulate. Also, C-kit signalling may play a role in oral hyperpigmentation, and indeed, C-kit is widely expressed in mesenchymal cells of the human oral cavity, including dental pulp cells and gingival fibroblasts [35]. In addition, the cases of oral hyperpigmentation reported to date do not appear to be drug dose-dependent (Table 2). Only a few oral mucosal hyperpigmentation cases caused by administration of imatinib mesylate to treat haematological malignancies have been reported. Hence, it remains speculative to suggest that imatinib mesylate may directly influence melanocyte C-kit signalling in the oral mucosa, activating melanogenesis. It is possible that genetic and/or other factors are also involved in the development of oral melanotic maculae. Finally, the time of onset of CML may be relevant; sometimes, patients are treated initially with hydroxyurea, which may also cause mucocutaneous hyperpigmentation and melanonychia [36-39].

\section{Conclusions}

The diagnosis of imatinib-associated oral pigmentation requires a thorough history-taking and clinical examination of the melanotic maculae. Medical and dental practitioners should be aware of possible oral mucosal hyperpigmentation in patients taking imatinib mesylate. The hyperpigmented lesions are benign; no treatment is required. However, annual follow-up is advisable to monitor changes in morphology or colour over time.

\section{Abbreviation}

ACTH: Adrenocorticotropic hormone; CML: Chronic myeloid leukaemia; MITF: Microphthalmia transcription factor

\section{Acknowledgements}

None.

Funding

None.

\section{Availability of data and materials}

The dataset supporting the conclusions of this article is included within the article (and its additional file).

\section{Authors' contributions}

BGP conceived and drafted the manuscript. GU revised the manuscript and made English editing and checked grammar. RM, GU, PM, SF, and ABG participated in the design and co-ordination of the study. PF performed the histopathological analysis. All authors have read and approved of the final manuscript.

Ethics approval and consent to participate

Not applicable.

\section{Consent for publication}

Written informed consent has been obtained from the patient for the publication of this case report and the accompanying images.

Competing interests

The authors declare that they have no competing interests.

\section{Publisher's Note}

Springer Nature remains neutral with regard to jurisdictional claims in published maps and institutional affiliations.

\section{Author details}

${ }^{1}$ Maxillo-Facial and Dental Unit, Fondazione Ca' Granda IRCCS Ospedale Maggiore Policlinico, University of Milan, Via Commenda 10, 20122 Milan, Italy. ${ }^{2}$ Department of Biomedical, Surgical and Dental Sciences, University of Milan, Milan, Italy. ${ }^{3}$ Unit of Anatomical Pathology, Fondazione IRCCS Ca' Granda Ospedale Maggiore Policlinico, University of Milan, Via Commenda 10, 20122 Milan, Italy.

Received: 25 October 2017 Accepted: 31 October 2017

Published online: 05 December 2017

References

1. Hassona Y, Sawair F, Al-Karadsheh O, Scully C (2016) Prevalence and clinical features of pigmented oral lesions. Int J Dermatol 55:1005-1013

2. Axell T (1976) A prevalence study of oral mucosal lesions in an adult Swedish population. Odontol Rev 36:1-103

3. Li CC, Malik SM, Blaeser BF, Dehni WJ et al (2012) Mucosal pigmentation caused by imatinib: report of three cases. Head Neck Pathol 6:290-295

4. Dereure O (2001) Drug-induced skin pigmentation. Epidemiology, diagnosis and treatment. Am J Clin Dermatol 2:253-262

5. Ciçek Y, Ertaş U (2003) The normal and pathological pigmentation of oral mucous membrane: a review. J Contemp Dent Pract 4:76-86

6. Meleti M, Vescovi P, Mooi WJ et al (2008) Pigmented lesions of the oral mucosa and perioral tissues: a flow-chart for the diagnosis and some recommendations for the management. Oral Surg Oral Med Oral Pathol Oral Radiol Endod 105:606-616

7. National Institute for Health and Care Excellence (2012) Guidance on the use of imatinib for chronic myeloid leukaemia, TA70. NICE, London

8. Scheinfeld N (2006) Imatinib mesylate and dermatology part 2: a review of the cutaneous side effects of imatinib mesylate. J Drugs Dermatol 5:228-231

9. Arora B, Kumar L, Sharma A, Wadhwa J, Kochupillai V (2004) Pigmentary changes in chronic myeloid leukemia patients treated with imatinib mesylate. Ann Oncol 15:358-359

10. Robert C, Soria JC, Spatz A, le Cesne A, Malka D, Pautier P et al (2005) Cutaneous side-effects of kinase inhibitors and blocking antibodies. Lancet Oncol 6:491-500

11. Tsao AS, Kantarjian H, Cortes J, O'Brien S, Talpaz M (2003) Imatinib mesylate causes hypopigmentation in the skin. Cancer 98:2483-2487

12. Ena P, Chiarolini F, Siddi GM, Cossu A (2004) Oral lichenoid eruption secondary to imatinib (Glivec). J Dermatolog Treat 15:253-255

13. Lim DS, Muir J (2002) Oral lichenoid reaction to imatinib (STI 571, Gleevec). Dermatology 205:169-171

14. Pascual JC, Matarredona J, Miralles J, Conesa V, Borras-Blasco J (2006) Oral and cutaneous lichenoid reaction secondary to imatinib: report of two cases. Int J Dermatol 45:1471-1473

15. Singh N, Bakhshi S (2007) Imatinib-induced dental hyperpigmentation in childhood chronic myeloid leukemia. J Pediatr Hematol Oncol 29:208-209

16. Singh O, Agrawal P, Agarwal A, Yadav S (2016) Imatinib induced dental hyperpigmentation chronic myeloid leukemia in adult female. J Assoc Physicians India 64:138 
17. Agrawal P, Singh O, Nigam AK, Upadhyay S (2015) Imatinib induced dental hyperpigmentation in chronic myeloid leukemia in an adult female. Indian J Pharmacol 47:685-686

18. Lewis DM (2009) Diffuse pigmentation of the palate. J Okla Dent Assoc 100:24-25

19. Wong M, Sade S, Gilbert M, Klieb HB (2011) Oral melanosis after tyrosine kinase inhibition with imatinib for chronic myelogenous leukemia: report of a case and review of the literature. Dermatol Online J 17:4

20. Mattsson U, Halbritter S, Mörner Serikoff E et al (2011) Oral pigmentation in the hard palate associated with imatinib mesylate therapy: a report of three cases. Oral Surg Oral Med Oral Pathol Oral Radiol Endod 111:e12-e16

21. Resende RG, Teixeira RG, Vasconcelos Fde $\mathrm{O}$ et al (2012) Imatinib associated hyperpigmentation of the palate in post-HSCT patient. J Cranio-MaxilloFacial Surgery 40:e140-e143

22. Roeker LE, Wolanskyj AP (2014) Imatinib-associated melanosis of the palate. Am J Hematol 89:564

23. Song HS, Kang HY (2014) Imatinib mesylate-induced hyperpigmentation of the nose and palate. Ann Dermatol 26:532-533

24. Lyne A, Creedon A, Bailey BM (2015) Mucosal pigmentation of the hard palate in a patient taking imatinib. BMJ Case Rep 16:2015

25. Meleti M, Mooi WJ, Casparie MK et al (2007) Melanocytic nevi of the oral mucosa - no evidence of increased risk for oral malignant melanoma: an analysis of 119 cases. Oral Oncol 43:976-981

26. Reddy GJ, Kanth MR, Kumar DR et al (2015) Oral malignant melanoma. J Clin Diagn Res 9:ZLO3

27. De Schepper S, Boucneau J, Lambert J, Messiaen L, Naeyaert JM (2005) Pigment cell-related manifestations in neurofibromatosis type 1: an overview. Pigment Cell Res 18:13-24

28. Kim IS, Kim ER, Nam HJ, Chin MO, Moon YH, MR O et al (1999) Activating mutation of GS alpha in McCune-Albright syndrome causes skin pigmentation by tyrosinase gene activation on affected melanocytes. Horm Res 52:235-240

29. Cinotti E, Couzan C, Perrot JL, Habougit C, Labeille B et al (2015) In vivo confocal microscopic substrate of grey colour in melanosis. J Eur Acad Dermatol Venereol 29:2458-2462

30. Alawi F (2013) Pigmented lesions of the oral cavity: an update. Dent Clin N Am 57:699-710

31. Hedin CA, Pindborg JJ, Axell T (1993) Disappearance of smoker's melanosis after reducing smoking. J Oral Pathol Med 22:228-230

32. Kauzman A, Pavone M, Blanas N et al (2004) Pigmented lesions of the oral cavity: review, differential diagnosis, and case presentations. J Can Dent Assoc 70:682-683

33. Callender VD, St Surin-Lord S, Davis EC, Maclin M (2011) Postinflammatory hyperpigmentation: etiologic and therapeutic considerations. Am J Clin Dermatol 12:87-99

34. Vera-Sirera B, Risueńo-Mata P, Ricart-Vaya JM et al (2012) Clinicopathological and immunohistochemical study of oral amalgam pigmentation. Acta Otorrinolaringol Esp 63:376-38

35. Barrett AW, Scully C (1994) Human oral mucosal melanocytes: a review. J Oral Pathol Med 23:97-103

36. Gagari E, Rand MK, Tayari L, Vastardis H, Sharma P et al (2006) Expression of stem cell factor and its receptor, C-kit, in human oral mesenchymal cells. Eur J Oral Sci 114:409-415

37. Kumar B, Saraswat A, Kaur I (2002) Mucocutaneous adverse effects of hydroxyurea: a prospective study of 30 psoriasis patients. Clin Exp Dermatol 27:8-13

38. McPherson T, Sherman V, Turner R (2009) Imatinib-associated hyperpigmentation, a side effect that should be recognized. J Eur Acad Dermatol Venereol 23:82-83

39. Romeo U, Palaia G, Fantozzi PJ, Tenore G, Bosco D (2015) A rare case of melanosis of the hard palate mucosa in a patient with chronic myeloid leukemia. Case Rep Dent 2015:9:817094

\section{Submit your manuscript to a SpringerOpen ${ }^{\circ}$ journal and benefit from:}

- Convenient online submission

- Rigorous peer review

- Open access: articles freely available online

- High visibility within the field

- Retaining the copyright to your article

Submit your next manuscript at $\boldsymbol{\sim}$ springeropen.com 